\title{
The Effect of Social Media INFLUENCERS FEATURED IN BEAUTY Care Products Advertisements on PURChASE INTENTION AMONG UCSI UNIVERSITY STUDENTS
}

\author{
Chin, Jia Yi \\ UCSI University \\ jiayi478@hotmail.com
}

\begin{abstract}
This research studies the influence of social media influencers featured in beauty care products advertisements on the purchase intention among UCSI University's students. By applying Ohanian's (1990) Source Credibility Theory, it studies the credibility of social media influencers on their expertise, trustworthiness, and attractiveness, and how these factors can influence students' perception towards social media influencers' credibility and their purchase intention for beauty care products. Besides, the study also aims to find out whether there is a significant difference between different ethnicities and their perception of the credibility of social media influencers. Questionnaires for the quantitative survey were distributed to 234 students from the Faculty of Social Science and Liberal Arts. Findings show that there is a significant relationship between the credibility of social media influencers, including expertise, trustworthiness, and attractiveness, with the purchase intention for beauty care products among UCSI University students (revise sentence). However, it proves that there is no significant difference between different ethnicities and their perception of the credibility of social media influencers. This research could contribute significantly to the beauty care brand fields where marketers can leverage the right social media influencers with the traits of expertise, trustworthiness, and attractiveness to help them to promote the brand to their audience and improve the sales.
\end{abstract}

Keywords: Social media influencer, advertisement, purchase intention, source credibility theory

\section{INTRODUCTION}

A social media influencer is an icon with a large number of followers on a social media platform and is trust in their respective fields (Forer, 2017; Lee, 2018). This new popular marketing strategy identifies social media influencers as imperative actors that influence the 
market. This strategy uses influencers with high popularity and followers on social media to collaborate with brands that are compatible with their lifestyle. Gradually, influencer marketing replaced traditional celebrity endorsement (Meltzer, 2018). There are numerous significantly proven results of this strategy among popular brands like Innisfree (Kancil Awards, 2017), Sunsilk (Marketing Interactive, 2014), and Loreal (Marketing Interactive, 2015). This indicates a new potential direction in social media marketing strategy to induce purchase among consumers. Their loyalty, credibility, and honesty are indeterminate. The uncertainty on the effectiveness of employing social media influencers for beauty care brands in Malaysia demands further research due to the absence of such study here.

This method is to use influencers with high popularity and followers on social media and invite them to collaborate with brands that are compatible with their lifestyle. Influencer marketing has gradually replaced traditional celebrity endorsement (Meltzer, 2018). Influencers come from various interests and fields where they manage their accounts and can have followers up to a few million (Claude, Malek \& Runnvall, 2018; Ren, Yeoh, Shan Ee \& Popovič, 2018).

Facebook and Instagram are a few of the most rapid-growing social media platforms in Malaysia from 2015 to 2017. Moreover, statistics have also proven that Malaysians are spending more time watching videos on social media platforms (Wong, 2017). Another statistic from Malaysia by Ngu (2018) states that marketers and business owners tend to apply influencer marketing in their businesses has grown gradually and that consumers tended to depend on influences for advice and tips before making a purchase.

There were some significant proven results by applying influencer marketing on some of the famous brands. Firstly, Innisfree has successfully sold 6500 customized cushion sets and increased sales by $30 \%$ by leveraging (justify data source) influencers to collaborate for the \#MyStyleMyCushion campaign. (Kancil Awards, 2016) Secondly, Sunsilk has also managed to attract many new followers and engagement and grow their share in 2013 by featuring five famous hijab bloggers in their 10 hijab styling videos for different events (Marketing Interactive, 2014). Thirdly, Loreal Malaysia collaborated with beauty influencers to make beauty tutorial videos on social media platforms, and eventually, they successfully reached a million audiences and increased their market share in the industry (Marketing Interactive, 2015).

However, collaborating with social media influencers has some problems. For instance, some of the social media influencers would take advantage of their popularity and make unreasonable requests from the industries (Chin, 2018). On the other side, some influencers would give honest reviews, or in some cases, bad reviews which, causes some brands to stay away from approaching them. Hence, influencer marketing has turned into a dilemma in whether influencers should be credible and always telling the truth or telling lies to maintain brands' positive sides (Claude, Malek \& Runnvall, 2018).

Additionally, influencers' loyalty and credibility are questioned if they become a spokesperson for more than one product of a similar category (Trip, Jensen \& Carlson, 2015). There are some examples among Malaysian influencers such as Lizz Chloe endorsing two different brands of hair care products and Charis Ow endorsing lipsticks of different brands.

Overall, Malaysia has gradually accepted the trend of influencer marketing and there was some significant success resulting from leveraging their influential power. Thus, there 
is a potential to further study on details on whether social media influencers are credible enough to endorse brands and how they can boost purchase intention.

There are many works of literature on celebrity endorsements (McCormick, 2016; Lim, Radzol, Cheah \&Wong, 2017; Abbas \& Afshan, 2018) but limited have studied on social media influencers. There were studies about eWOM and bloggers (Hsu, Lin \& Chiang, 2013; Lu, Chang \& Chang, 2014; Erkan \& Evans, 2016; Wu \& Lee, 2012) but they are not fully applicable to represent social media influencers as a whole. Although, some researchers have studied beauty bloggers or vloggers. These studies have been conducted in many countries such as United States (Davis, 2016; Lee, 2018), Indonesia (Ananda \& Wandebori, 2016; Rahmi et al, 2017), Saudi Arabia (Konstantopoulou, 2018), Sweden (Linnér, Taha, \& Carlsson, 2018) and Macau (Liu et al, 2018). No such study has been conducted covering the Malaysian context. Thus, the gap can be filled by conducting such research at UCSI University. This study covers the effect of social media influencers featured in beauty care products advertisements on purchase intention among UCSI University students.

\section{LITERATURE REVIEW \\ Different Ethnic and their Perception towards Credibility of Social Media Influencers}

Many research articles from different countries and contexts have studied the credibility of social media influencers and how they influence consumers' attitudes, brand awareness, and purchase intention. The countries where each study was conducted included United States, Indonesia, Sweden, Macau, and Saudi Arabia. (Konstantopoulou et al, 2018; Davis, 2016; Rahmi et al, 2017; Linnér, Taha, \& Carlsson, 2018; Liu et al, 2018, Lee, 2018)

For the studies conducted in the United States (Davis, 2016; Lee, 2018), the researchers obtained relatively positive results. They concluded that most of the ethnics would have a positive attitude and purchase intention towards videos and recommendations by influencers like vloggers however in Davis's results it was found that it showed no sign of high purchase intention among consumers because they were not showing interest or demand on the product studied. Vloggers with physical and social attractiveness commonly obtain more positive parasocial interaction from consumers (Liu et.al, 2018). Additionally, trustworthiness is also important to generate purchase intention, specifically for the fashion industry in Sweden (Linnér, Taha, \& Carlsson, 2018).

Contrastingly, for the research conducted in Indonesia and Saudi Arabia (Rahmi et al, 2017; Konstantopoulou et al, 2018), they discovered that most of the respondents in both countries perceived influencers as not being credible and authentic compared to traditional celebrities. Indonesian consumers trust their family's and friends' opinions more, while Saudi consumers prefer a positive experience through the influencers first. Based on the research findings above, it can be observed that each ethnicity has a similar perception towards the credibility of social media influencers, regardless of having positive or negative perceptions. Thus, a hypothesis was proposed:

- H1: There are significantly different perceptions towards the credibility of social media influencers among different ethnicities. 


\section{The Credibility of Social Media Influencers and Purchase Intention}

In Nugraha's and Setyanto's (2018), Davis's (2016), and Lee's (2018) study, they have concluded that the credibility of social media influencers has a positive impact on consumers' attitudes, brand awareness, and purchase intention. The credibility of social media influencers can positively increase consumers' perception and acceptance of the information's usefulness (Lee, 2018; Erdogan, 1999). This claim is supported by the market reports by Gesenhues (2013) and Nielsen (2015) that 70\% to $90 \%$ of consumers get influenced by online reviews before making a purchase decision.

However, negative results were found by Lim et al (2017) and Rahmi's, Sjabadhyni's, and Sekarasih's (2017) that the credibility of social media influencers does not have a significant impact on consumers' attitude and purchase intention. Both studies found that respondents of their contexts did not perceive influencers as credible and knowledgeable compared to traditional endorsers. Since most of the findings concluded that there is a significant relationship between the credibility of social media influencers and purchase intention, this hypothesis can be drawn that:

- H2: There is a significant relationship between the credibility of social media influencers and the purchase intention of beauty care products among UCSI University students.

\section{The Expertise of Social Media Influencers and Purchase Intention}

It has been found some empirical studies have found that the expertise of social media influencers can influence consumers' purchase intention positively (Ananda \& Wandebodi, 2016; Soat, 2014; Wen, Tan \& Chang, 2009). Their expertise is important as consumers perceive themselves as having adequate knowledge to internalise before making any purchase decision (Goldsmith, Lafferty \& Newell, 2000; Lowry, Wilson \& Haig, 2014; Soat, 2014). However, the influence of influencers' expertise is not applicable for hedonic products, unlike utilitarian products (Wen, Tan \& Chang, 2009). Hedonic products benefit consumers through pleasure, fun, and enjoyment.

Different from other literature, Linnér, Taha, and Carlsson (2018) claim that an influencer's expertise does not significantly influence consumers' purchase intention. Given this, social status was found to be more significant than expertise (Zhao, Liu, He, Lin, \& Wen, 2016. Most findings have proven the significant relationship between social media influencers' expertise and consumers' purchase intention, therefore a hypothesis has been drawn that:

- H2(a): There is a significant relationship between the expertise of social media influencers and the purchase intention of beauty care products among UCSI University students.

\section{Trustworthiness of Social Media Influencers and Purchase Intention.}

Literature has explained positive results regarding the relationship between social media influencers' trustworthiness and consumers' purchase intention (Ananda \& Wandebodi, 2016; Goldsmith, Lafferty \& Newell, 2000; Linnér, Taha, \& Carlsson, 2018). Trustworthiness 
is gained from an interaction between influencers and consumers that builds familiarity and trust. From here, consumers perceive the information obtained from the influencers as useful (Hsu, 2013) and internalise the information received (Goldsmith, Lafferty \& Newell, 2000).

In some other literature with contrast findings, the trustworthiness of social media influencers does not have a significant impact on consumers' purchase intention (Rahmi, Sjabadhyni \& Sekarasih, 2017; Schiffman \& Wisenblit, 2015). It has been found that their respondents trust traditional celebrities or their family and friends more than social media influencers. Specifically, consumers from collectivistic countries such as Indonesia tend to place more trust in traditional celebrities (Pornpitakpan, 2004). With the inconsistent findings regarding the impact of social media influencers' trustworthiness on consumers' purchase intention, it is hypothesized that:

- $\mathrm{H} 2(\mathrm{~b})$ : There is a significant relationship between the trustworthiness of social media influencers and the purchase intention of beauty care products among UCSI University students.

\section{Attractiveness of Social Media Influencers and Purchase Intention.}

There are some positive findings regarding the relationship between the attractiveness of social media influencers and consumers' purchase intention (Abidin, 2016; Liu et al, 2018; Nugraha \& Setyanto, 2018). Attractive influencers are often used in promoting products to leverage their beauty in making the advertisements more appealing (Abidin, 2016). The attractiveness builds parasocial interaction (Liu et al, 2018), impresses and keeps consumers entertained (Nugraha \& Setyanto, 2018). Additionally, the influencers' attractiveness moves the consumers' desire to be attractive like the influencers (Kelman, 1961). Thus, build brand awareness that leads to purchase intention.

However, Norton (2007) found that familiarity with the attractive influencers may lead to an inferiority complex as they think they are unlikeable, hence reduces the purchase intention potential. Other than that, a few studies did not find any significant relationship between influencers' attractiveness and consumers' purchase intention (Ananda \& Wandebodi, 2016; Linnér, Taha \& Carlsson, 2018). With some findings proving the significant relationship between influencers' attractiveness and consumers' purchase intention, it can be hypothesised that:

- H2(c): There is a significant relationship between the attractiveness of social media influencers and the purchase intention of beauty care products among UCSI University students.

\section{THEORETICAL AND CONCEPTUAL FRAMEWORK}

The first theory applied is Source Credibility Theory (SCT) (Berlo, Lemert \& Mertz, 1969; Hovland \& Weiss, 1952) that explains the persuasiveness of communication through the perceived credibility of the communication source. According to Ohanian (1990), the determinants of source credibility include expertise, trustworthiness, and attractiveness. Dimensions to assess one's expertise include expert, experienced, knowledgeable, qualified, 
and skilled. Dimensions used to access trustworthiness include dependable, honest, reliable, sincere, and trustworthy. As for attractiveness, dimensions like attractive, classy, beautiful, elegant, and sexy are used. Expertise, trustworthiness, and attractiveness can influence the credibility of the communicator (Hovland, 1953; Baker \& Churchill, 1977).

The second theory used is the Engel, Kollat, and Blackwell model (1978) that explains the consumers' decision process when dealing with a few alternatives or options. The third stage of the process is the evaluation of alternatives, explained with SCT where consumers access influencers' credibility before making a purchase decision.

The conceptual framework in Figure 1 shows the relationship between "Social Media Influencers featured in Beauty Care Products Advertisements" and "Purchase Intention among UCSI University's Students". The former is an independent variable while the latter is a dependent variable. A more detailed research framework is explained in Figure 2.

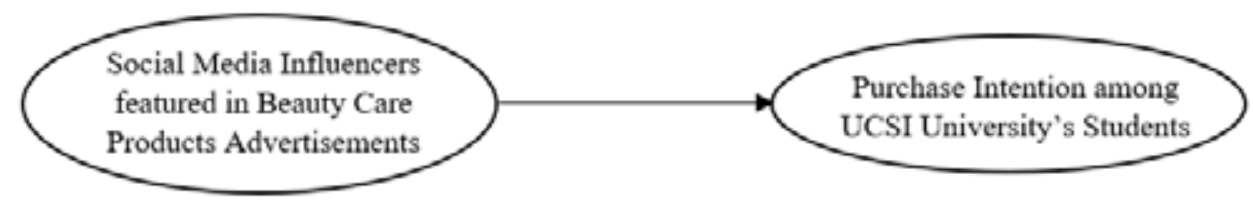

Figure 1: Conceptual Framework of The Relationship between Social Media Influencers Featured in Beauty Care Products Advertisement and Purchase Intention

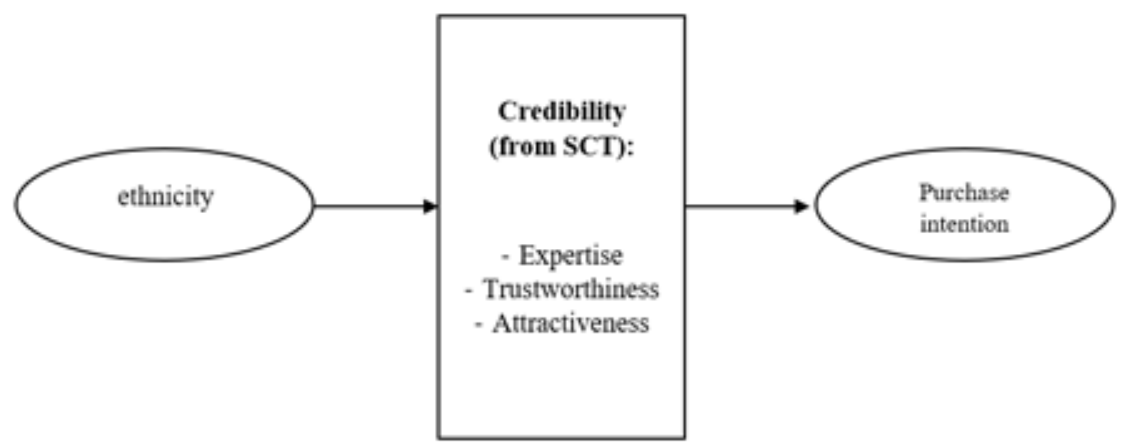

\section{Figure 2: Detailed Conceptual Framework of The Relationship between Social Media Influencers Featured in Beauty Care Products Advertisement and Purchase Intention}

\section{METHODOLOGY}

This study has employed a quantitative method using survey data collection at UCSI University, Kuala Lumpur. The participants were chosen among the students from the Faculty of Social Sciences and Liberal Arts (FOSSLA) as the undergraduate students are in the group of young adults. There were about 600 students in FOSSLA and based on Krejcie and Morgan, 234 samples needed to be conducted. However, 300 samples have been conducted to avoid invalid responses. 


\section{Instrument}

The survey questionnaire consisted of Section 1: Demographic Profile, Section 2: Expertise of Social Media Influencers, Section 3: Trustworthiness of Social Media Influencers, Section 4: Attractiveness of Social Media Influencers, and Section 5: Purchase Intention. Items for expertise, trustworthiness, and attractiveness were adopted from Ohanian (1990). While items for purchase intention were adapted from Kumar (2011). The semantic differential scale was applied in Section 2, Section 3, and Section 4 while the 5-point Likert scale was being applied in Section 5. A pilot test on 30 respondents was conducted to test the reliability of the instrument. Each section had obtained more than 0.7 Cronbach's Alpha value indicating the instrument was able to yield consistent findings.

\section{Participants}

The questionnaire has been distributed to 300 samples, but only 234 valid questionnaires were considered and calculated. Based on Table 1, there were 122 male respondents $(52.1 \%)$, which is slightly higher than the number of female respondents which were 112 (47.9\%). Most of the respondents were ranging from 21 to 23 years old, which comprised 148 of them (63.2\%). As for the nationality, 181 of the respondents are Malaysians, which comprised $77.4 \%$ of the respondents. Only the rest of the 52 respondents $(22.2 \%)$ were from other countries. Among the respondents, $178(76.1 \%$.) were of Chinese ethnicity. Furthermore, most respondents were from BA in Mass Communication programme (60.7\%). The least was BA in English Language and Communication (14.1\%). Lastly, majority of the respondents were in their third year (52.6\%).

Table 1: Respondents' Demographic Characteristics $(n=234)$

\begin{tabular}{|c|c|c|}
\hline Subject & Frequency & Percentage (\%) \\
\hline \multicolumn{3}{|l|}{ Age: } \\
\hline $18-20$ & 60 & 25.6 \\
\hline $21-23$ & 148 & 63.2 \\
\hline above 23 & 26 & 11.1 \\
\hline \multicolumn{3}{|l|}{ Gender: } \\
\hline Male & 122 & 36.8 \\
\hline Female & 112 & 63.2 \\
\hline \multicolumn{3}{|l|}{ Nationality: } \\
\hline Malaysian & 181 & 77.4 \\
\hline Others & 52 & 22.2 \\
\hline \multicolumn{3}{|l|}{ Ethnicity: } \\
\hline Malay & 5 & 2.1 \\
\hline Chinese & 178 & 76.1 \\
\hline Indian & 15 & 6.4 \\
\hline Other & 36 & 15.4 \\
\hline
\end{tabular}




\begin{tabular}{lcc}
\hline Programme: & & \\
BA in Mass Communication & 142 & 60.7 \\
BA in English Language and Communication & 33 & 14.1 \\
BA in Psychology & 59 & 25.2 \\
\hline Year: & 41 & \\
First year & 70 & 17.5 \\
Second year & 123 & 29.9 \\
Third year & & 52.6 \\
\hline
\end{tabular}

\section{FINDINGS}

H1: There are significantly different perceptions towards the credibility of social media influencers among different ethnicities.

It has been found that there is no significant difference between different ethnicities' perceptions towards the credibility of social media influencers. The result shown in Table 2 explains the ANOVA test where the F value is 1.396 while the significant value is 0.245 , which is higher than the significant level $(\mathrm{a}=0.05)$. Therefore, $\mathrm{H} 1$ has been rejected.

\section{Table 2: ANOVA Test Result for the Relationship between different Ethnic and their Perception towards Credibility of Social Media Influencers $(n=234)$}

\begin{tabular}{lccc}
\multicolumn{1}{c}{ Variables } & Significant Value & F & Results \\
$\begin{array}{l}\text { Respondents Ethnic - Credibility of Social } \\
\text { Media Influencers }\end{array}$ & 0.245 & 1.396 & Rejected \\
\hline
\end{tabular}

H2: There is a significant relationship between the credibility of social media influencers and the purchase intention of beauty care products among UCSI University students.

Through the Pearson Correlation test in Table 3, it has been revealed that there is a significant correlation between the credibility of social media influencers and the purchase intention for beauty care products among UCSI University students $(r=0.432 ; p<0.05)$. This indicates a positive relationship between them. Therefore, $\mathrm{H} 2$ has been accepted. The value $\mathrm{r}=0.432$ indicates a moderate level of relationship based on Guilford's 'Rule of Thumb'.

H2(a): There is a significant relationship between the expertise of social media influencers and the purchase intention of beauty care products among UCSI University students.

The Pearson Correlation test in Table 3, has revealed that there was a significant correlation between the expertise of social media influencers and the purchase intention for beauty care products among UCSI University students. ( $\mathrm{r}=0.383$, $\mathrm{p}<0.05)$. Therefore $\mathrm{H} 2(\mathrm{a})$ has been accepted. There is a positive relationship but in a moderate strength level of relationship. 
H2(b): There is a significant relationship between the trustworthiness of social media influencers and the purchase intention of beauty care products among UCSI University students.

From Table 3, the Pearson correlation test conducted shows that there is a significant correlation between the trustworthiness of social media influencers and the purchase intention for beauty care products among UCSI University students. $(r=0.298, p<0.05)$. Therefore H2(b) has been accepted. The relationship is positive and falls into the weak category according to Guilford's 'Rule of Thumb'.

H2(c): There is a significant relationship between the attractiveness of social media influencers and the purchase intention of beauty care products among UCSI University students.

Pearson Correlation test shown in Table 3 explains that there is a significant correlation between the attractiveness of social media influencers and purchase intention for beauty care products among UCSI University students. $(\mathrm{r}=0.356, \mathrm{p}<0.05)$. Therefore $\mathrm{H} 2(\mathrm{c})$ has been accepted. The relationship is positive and the $r$-value indicates a moderate strength level of the relationship.

\section{Table 3: Pearson Correlation Test Result for the Relationship between Credibility, Expertise, Trustworthiness, Attractiveness of Social Media Influencers and Purchase Intention $(n=234)$}

\begin{tabular}{lccc}
\multicolumn{1}{c}{ Correlation } & $\begin{array}{c}\text { Significant } \\
\text { Value }\end{array}$ & R & Result \\
$\begin{array}{l}\text { Credibility of Social Media Influencers } \rightarrow \text { Purchase } \\
\text { Intention }\end{array}$ & 0.000 & 0.432 & Accepted \\
$\begin{array}{l}\text { Expertise of Social Media Influencers } \rightarrow \text { Purchase } \\
\text { Intention }\end{array}$ & 0.000 & 0.383 & Accepted \\
$\begin{array}{l}\text { Trustworthiness of Social Media Influencers } \rightarrow \\
\text { Purchase Intention }\end{array}$ & 0.000 & 0.298 & Accepted \\
$\begin{array}{l}\text { Attractiveness of Social Media Influencers } \rightarrow \\
\text { Purchase Intention }\end{array}$ & 0.000 & 0.356 & Accepted \\
\end{tabular}

\section{DISCUSSION}

$\mathrm{H} 1$ has been rejected, as it has been found that there is no significant difference between different ethnicities' perceptions towards the credibility of social media influencers. The result is consistent with the studies by Davis (2016), Lee (2018), Liu et al (2018), Rahmi et. al (2017), and Konstantopoulou (2018) which revealed that there is no difference between different ethnic's perception towards the credibility of social media influencers. The respondents were consistent regardless of positive or negative attitudes towards the credibility of social media influencers. 
The result is inconsistent with Rashid, Nallamuthu and Sidin (2002) finding which found that different ethnic in Malaysia has different perception towards celebrity endorsers. The inconsistency could be explained by McLuhan's (1960) "global village" theory which explained greater communication has removed traditional boundaries, brought people closer, and exposed them to the same culture. Furthermore, the year gap between this study and Rashid, Nallamuthu and Sidin (2002) could also be the reason for the results' inconsistency.

The second hypothesis was accepted concluding the significant relationship between the trustworthiness of social media influencers and the purchase intention for beauty care products among UCSI University students. The result is consistent with the findings by Nugraha and Setyanto (2018), Davis (2016), and Lee (2018) which also concluded that the credibility of social media influencers has a positive effect on consumers' brand awareness, perception of information usefulness, and purchase intention. However, it is inconsistent with Lim et al.'s (2017) negative finding. This inconsistency may be subjected to the smaller number of respondents and their wider age range. According to Opinion Leadership theory, opinion leaders can only influence an audience within the same age group (Holbert \& Weinmann, 2017).

Next, the relationship between the expertise of social media influencers and the purchase intention for beauty care products among UCSI University students was found significant; supporting H2a. The result is similar to Ananda and Wandebodi's (2016), Soat's (2014), and Wen, Tan, and Chang's (2009) findings which concluded that expertise is a significant element enabling consumers to trust the influencers and make a purchase decision. However, the result is not consistent with Linnér, Taha, \& Carlsson's (2018) findings. The inconsistency may be caused by the different contexts of each research, which includes the wider age range up to 76 years old used in Linnér, Taha, \& Carlsson's (2018) study.

Similarly, $\mathrm{H} 2 \mathrm{~b}$ was accepted concluding the significant relationship between the trustworthiness of social media influencers and the purchase intention for beauty care products among UCSI University students. The result is consistent with Ananda and Wandebodi's (2016), Goldsmith, Lafferty \& Newell's (2000), and Linnér, Taha, \& Carlsson's (2018) findings that trustworthiness is essential for consumers to internalise influencers' message and make a purchase decision. However, it is not consistent with Rahmi, Sjabadhyni, and Sekarasih's (2017) which found that the trustworthiness of influencers does not have a positive impact on consumers' purchase decisions. The inconsistency can be caused by collecting data in a collectivistic country where people trust traditional endorsers more (Pornpitakpan, 2004). Besides, Rahmi, Sjabahyni, and Sekarasih (2017) used a different sampling that is female respondents among the age range 18 to 34 years old, unlike this study.

It was also found that the relationship between the attractiveness of social media influencers and the purchase intention for beauty care products among UCSI University students is significant, supporting H2c. The result is consistent with Kelman's (1961), Liu et. al's (2018), and Nugraha and Setyanto's (2018) studies which concluded that attractive influencers trigger the need for beauty among consumers, and strengthen the relationship with the consumers. Thus, create brand awareness and purchase intention. In contrast, it is inconsistent with Ananda and Wandebodi's (2016) study that found that influencers' attractiveness does not contribute to consumers' purchase intention. The inconsistency can be caused by a different context which was based in Indonesia with different respondents' demographic groups and social media usage. 
Both practical and theoretical implications are discussed in this study. Theoretically, the proposed framework is based on the SCT where the source credibility of social media influencers consists of the expertise of social media influencers, the trustworthiness of social media influencers, and the attractiveness of social media influencers. Then, the framework also proposed that the credibility of social media influencers will have a positive impact on the purchase intention for beauty care products among UCSI University Students. The SCT is found applicable for the studies of social media influencers and consumer's decision-making on beauty products.

The practical implication is targeted to the marketers and beauty care product business owners. It is imperative for marketers of beauty care products to choose the right social media influencers who can influence a purchase. Specifically for beauty care brands targeted at Generation Z, a social media influencer should have these characteristics; high credibility, an expert of the product to be endorsed, trustworthiness and attractiveness. Selecting a suitable social media influencer with the right characteristics is imperative to create more efficient campaigns and marketing.

The finding from this research study can be beneficial to the markets and industries especially those who find it difficult and challenging to market their brands and products online. Leveraging social media influencers to help brands reach a wider audience base is an effective method. However, at the same time, brands need to choose the right influencers which best fit their brands and products type. In this research, it has already been proven that there is a significant relationship between the credibility (expertise, trustworthiness, and attractiveness) of the social media influencers and the purchase intention for beauty care products among UCSI University students. Brands are to consider social media influencers with high credibility, expertise about the products endorsed, trustworthiness to carry a believable message, and attractiveness for them to be liked and admired by their audience.

Social media marketing can be used and targeted heavily on the university students of the millennial generation and generation $\mathrm{Z}$ who are the heaviest social media users. Overall, this research has provided a better understanding of how consumers perceive social media influencers in endorsing beauty care products. From the marketing perspective, beauty brands need to choose the right influencers to create more efficient campaigns and marketing.

\section{CONCLUSION}

It is concluded that firstly, there is no significant difference between different ethnics' perception towards the credibility of social media influencers, which is supported by the "global village" theory by McLuhan (1960) that increasingly interconnected communication has caused people to be exposed to the same culture, hence they are gradually trusting the credibility of social media influencers. Besides, it has also been concluded that there is a significant relationship between the credibility of social media influencers, including their expertise, trustworthiness, and attractiveness, and the purchase intention for beauty care products by UCSI University students. It has been proven that the influencers' credibility enables consumers to internalise their information, improve brand awareness and purchase intention. 
In a nutshell, it can be proven that there is a positive effect of social media influencers featured in beauty care products advertisements on purchase intention among UCSI University students.

\section{REFERENCES}

Abbas, A., Afshan, G., Aslam, I., \& Ewaz, L. (2018). The effect of celebrity endorsement on customer purchase intention: A comparative study. Current Economics and Management Research, 4(1), 1-10.

Abidin, C. (2016). "Aren't these just young, rich women doing vain things online?": Influencer selfies as subversive frivolity. Social Media+ Society, 2(2).

Ananda, A. F., \& Wandebori, H. (2016). The impact of drugstore makeup product reviews by beauty vlogger on YouTube towards purchase intention by undergraduate students in Indonesia. In International Conference on Ethics of Business, Economics, and Social Science, 255-263.

Berlo, D. K., Lemert, J. B., \& Mertz, R. J. (1969). Dimensions for evaluating the acceptability of message sources. Public Opinion Quarterly, 33(4), 563-576.

Chin, C. (2018, December 22). Malaysian hotels afraid to turn away influencers asking for free stay. The Star. Retrieved from https://www.star2.com/travel/2018/12/21/malaysianhotels-afraid-turn-away-social media-influencers-asking-free-stay/

Claude, L., Malek, P., \& Runnvall, L. (2018). Influencers impact on the decision-making among generation $Y \& Z$ Swedish females when purchasing fast fashion. (Unpublished Bachelor Degree Thesis). Jonkoping University. Sweden.

Davis, V. F. (2016). Trusting the guru: studying the effects of online beauty guru reviews on consumer opinion forming and purchase intent of cosmetics (Doctoral dissertation). University of Texas at Austin, USA. Retrieved from https://repositories.lib.utexas.edu/handle/2152/38098

Engel, J., Kollat, D., Blackwell, R. (1978). Consumer Behaviour. New York: Dryden Press.

Erdogan, B. Z. (1999). Celebrity endorsement: A literature review. Journal Of Marketing Management, 15(4), 291-314.

Erkan, I., \& Evans, C. (2016). The influence of eWOM in social media on consumers' purchase intentions: An extended approach to information adoption. Computers in Human Behavior, 61, 47-55.

Forer, L. 2017. The lowdown of social media influencers. Marketing Profs. Retrieved from https:/www.marketingprofs.com/chirp/2017/31547/the-lowdown-on-social-mediainfluencers-infographic

Gesenhues, A. (2013). Survey: $90 \%$ of customers say buying decisions are influenced by online reviews. Available from: http://marketingland.com/survey-customers-more-frustratedbyhow-long-it-takes-to-resolve-a-customer-service-issue-than-the-resolution-38756+

Ghazali, E., Soon, P. C., Mutum, D. S., \& Nguyen, B. (2017). Health and cosmetics: Investigating consumers' values for buying organic personal care products. Journal of Retailing and Consumer Services, 39, 154-163.

Goldsmith, R. E., Lafferty, B. A., \& Newell, S. J. (2000). The impact of corporate credibility and celebrity credibility on consumer reaction to advertisements and brands. Journal of Advertising, 29(3), 43-54. 
Holbert, R. L., Weinmann, C., \& Robinson, N. (2017). Permanent entertainment and political behavior. Permanently online, permanently connected: Living and communicating in a POPC world. New York: Routledge.

Hovland, C. I. \& Weiss, W. 1952. The influence of source credibility on communication effectiveness. The Public Opinion Quarterly, 15: 635-650

Hovland, C. (1953). Communication and persuasion: Psychological studies of opinion change. New Haven: Yale University Press.

Hsu, C., Lin, C.J., \& Chiang, H. (2013). The effects of blogger recommendations on customers' online shopping intentions. Internet Research, 23(1), 69-88.

Inni Puppet Show. (2017). Kancil Awards. Retrieved from https://www.kancilawards.com/ winners/entry/2017/2044.

Kelman, H. C. (1961). Processes of opinion change. Public Opinion Quarterly, 25(1), 57-78.

Konstantopoulou, A., Rizomyliotis, I., Konstantoulaki, K., \& Badahdah, R. (2018). Improving SMEs' competitiveness with the use of Instagram influencer advertising and eWOM. International Journal of Organizational Analysis, 27(2), 308-321. https://doi.org/10.1108/ IJOA-04-2018-1406.

Kumar, A. (2011, April 4,). Celebrity endorsements and its impact on consumer buying behaviour. Available at SSRN: https://ssrn.com/abstract=1802531 or http://dx.doi. org/10.2139/ssrn.1802531

Lee, K. (2018). The influence of beauty-related YouTube content on consumers' purchase intention. (Unpublished master's thesis). University of Tennessee. USA. Retrieved from https:// trace.tennessee.edu/utk_gradthes/5151.

Lim, X. J., Radzol, A. M., Cheah, J., \& Wong, M. W. (2017). The impact of social media influencers on purchase intention and the mediation effect of customer attitude. Asian Journal of Business Research, 7(2), 19-36.

Linnér, E., Taha, S., \& Carlsson, J. (2018). What characterizes an influential Instagram fashion influencer? A descriptive research. (Unpublished bachelor thesis). Linnaeus University, Sweden. Retrieved from https://www.diva-portal.org/smash/get/diva2:1221633/ FULLTEXT01.pdf.

Liu, M. T., Kei, P. L. I., Liu, Y., \& Tseng, T. H. (2018, July). How video blogger (vlogger) affects parasocial interaction and brand. In Proceeding of 2018 Global Marketing Conference, (pp. 148-153). Seoul: Global Alliance of Marketing \& Management Associations.

Lowry, P. B., Wilson, D. W., \& Haig, W. L. (2014). A picture is worth a thousand words: Source credibility theory applied to logo and website design for heightened credibility and consumer trust. International Journal of Human-Computer Interaction, 30(1), 63-93.

Marketing Interactive. (2014, September 15). How Sunsilk arrested stagnating growth in Malaysia. Retrieved from https://www.marketing-interactive.com/sunsilk-arrestedstagnatinggrowth-malaysia/

Marketing Interactive, (2015, December 11). Case study: L'Oreal goes beyond skin deep with Twitter. Retrieved from https://www.marketing-interactive.com/case-study-loreal-goesbeyond-skin-deep-with-twitter.

McCormick, K. (2016). Celebrity endorsements: Influence of a product-endorser match on Millennials attitudes and purchase intentions. Journal of Retailing and Consumer Services, $32,39-45$. 
McLuhan, M. (1960). Classroom without walls. In E. Carpenter \& M McLuhan, Explorations in communication, (pp. 1-3). Boston: Beacon Press

Meltzer, L. (2018). Social media "influencers" add a new twist to advertising. CBS News Retrieved from: https://www.cbsnews.com/news/social-media-influencers-brandadvertising/.

Ngu, T. (2018). Influencer marketing technology landscape 2018. Starngage. Retrieved from: https://starngage.com/influencer-marketing-technology-landscape-2018/.

Nielsen (2015, September 28). Malaysians Trust Word-of-Mouth Recommendations Most. Retrieved from https://www.nielsen.com/my/en/insights/news/2015/malaysianstrustword-of-mouth-recommendations-most.html.

Norton, M. I., Frost, J. H., \& Ariely, D. (2007). Less is more: The lure of ambiguity, or why familiarity breeds contempt. Journal of Personality and Social Psychology, 92(1), 97.

Nugraha, A., \& Setyanto, R. P. (2018). The effects of vlogger credibility as marketing media on brand awareness to customer purchase intention. Journal of Research in Management, 1(2). $1-10$

Ohanian, R. (1990). Construction and validation of a scale to measure celebrity endorsers' perceived expertise, trustworthiness, and attractiveness. Journal of Advertising, 19(3), 39-52. Pornpitakpan, C. (2004). The persuasiveness of source credibility: A critical review of five decades' evidence. Journal of Applied Social Psychology, 34, 243-281. doi:10.1111/j.1559-1816.2004.tb02547.x

Rahmi, Y., Sekarasih, L., \& Sjabadhyni, B. (2016). The influence of beauty vlog on perceived source credibility and purchase intention. Makara Hubs-Asia, 20(2), 13-23.

Ren, J., Yeoh, W., Shan Ee, M., \& Popovič, A. (2018). Online consumer reviews and sales: Examining the chicken-egg relationships. Journal of the Association for Information Science and Technology, 69(3), 449-460.

Schiffman, L. G., \& Wisenblit, J. (2015). Consumer Behavior (11 ed.). New Jersey: Prentice-Hall.

Tripp, C., Jensen, T. D., \& Carlson, L. (1994). The effects of multiple product endorsements by celebrities on consumers' attitudes and intentions. Journal of Consumer Research, 20(4), 535-547.

Soat, M. (2014). Marketers forge ahead on social media spending despite uncertainties, research shows. AMA. Retrieved July 2, 2017, from https://www.ama.org/publications/ eNewsletters/Marketing-News-Weekly/Pages/cmo-survey.aspx

Wen, C., Tan, B. C., \& Chang, K. T. T. (2009). Advertising effectiveness on social network sites: an investigation of tie strength, endorser expertise and product type on consumer purchase intention. ICIS 2009 Proceedings, 151.

Wong, C. (2017, April 26). Facebook \& Instagram are the fastest growing social media platforms in Malaysia. Retrieved from http://blog.bigcast.my/2017/04/facebookinstagram-are-fastestgrowing-social-media-malaysia.html

Wu, W. L., \& Lee, Y. C. (2012). The effect of blog trustworthiness, product attitude, and blog involvement on purchase intention. International Journal of Management $\mathcal{E}$ Information Systems (IJMIS), 16(3), 265-276.

Zhao, W., Liu, J., He, Y., Lin, C. \& Wen, J. (2016). A computational approach to measuring the correlation between expertise and social media influence for celebrities on microblogs. World Wide Web, 19(5), 865-886. 